\title{
ARTICLE
}

Epidemiology

\section{Evaluation of efficacy and safety of sorafenib in kidney cancer patients aged 75 years and older: a propensity score-matched analysis}

\author{
Katsunori Tatsugami ${ }^{1}$, Mototsugu Oya ${ }^{2}$, Koki Kabu ${ }^{3}$ and Hideyuki Akaza ${ }^{4}$
}

BACKGROUND: The average age of patients diagnosed with renal cell carcinoma (RCC) is increasing, but a limited number of reports have described therapy of tyrosine kinase inhibitor for elderly RCC patients. Hence, we analysed the efficacy and safety of sorafenib in elderly patients aged $\geq 75$ years with advanced RCC.

METHODS: Data were extracted from $<75$-year-old and $\geq 75$-year-old patient groups, matching those demographics considered to affect prognosis. Differences in patients' characteristics, dose modification, adverse events, tumour response, progression-free survival, and renal function (glomerular filtration) were evaluated between the groups.

RESULTS: From 2536 and 703 patients aged $<75$ and $\geq 75$ years, respectively, 397 pairs were matched. Median daily dose was higher and duration of treatment longer in patients $<75$ years; however, progression-free survival and tumour response were similar in both age groups. Incidence of all adverse events was not significantly different between groups. The proportion of patients discontinuing treatment was higher in patients $\geq 75$ years, but there was no significant difference between groups in the number patients discontinuing due to adverse events.

CONCLUSIONS: For patients aged $\geq 75$ years, sorafenib treatment had minimal additional negative impact compared to younger patients and showed similar efficacy and safety without reducing renal function.

British Journal of Cancer (2018) 119:241-247; https://doi.org/10.1038/s41416-018-0129-3

\section{INTRODUCTION}

Renal cell carcinoma (RCC) is the third most common cancer among urological cancers, and accounts for $3 \%$ of all cancers in adults. ${ }^{1}$ The incidence of RCC peaks between ages 60 and 70 years. ${ }^{2}$ Patients with RCC aged $>65$ years account for about $50 \%$ of those diagnosed in the USA and almost $70 \%$ of those dying from this tumour. ${ }^{3,4}$ It is anticipated that the incidence of RCC patients will account for more than $50 \%$ due to recent ageing society.

Since the development of molecular targeted agents, especially those that inhibit the vascular endothelial growth factor receptors (VEGFRs), a paradigm shift has occurred in the treatment of patients with RCC over the past decade, leading to improvements in the prognoses of these patients.

Elderly patients are a heterogeneous group in which there may be disparities between chronological age and biological age, and the natural history of the disease and response to the treatment may be different from those of younger patients. The International Society of Geriatric Oncology indicated that 'when considering the most appropriate drug to use in a particular patient, the toxicity profiles of the individual targeted agents and any implications for specific comorbid conditions - should be taken into account'.5 Specifically, for the treatment of elderly patients with cancer, the guidelines suggest the following should be considered: (i) any decrease in the functional capacity of the major organs and the impact of treatment due to complication; (ii) choice of therapeutic agents and any necessary dose reductions due to impaired renal or liver function; and (iii) the impact of social factors and any decrease in quality of life should be considered.

To investigate the impact of older age on the efficacy and safety of sorafenib in the treatment of advanced RCC, we retrospectively analysed the data from real-world use of sorafenib in patients aged $\geq 75$ years.

\section{METHODS}

Study population

As reported in our earlier publications, ${ }^{6,7}$ these data were derived from Japanese patients with histologically or cytologically confirmed unresectable or metastatic RCC who started sorafenib treatment between February 2008 and September 2009. On the basis of a requirement from the Pharmaceutical and Medical Devices Agency (PMDA), these real-world data were collected

\footnotetext{
${ }^{1}$ Department of Urology, Graduate School of Medical Science, Kyushu University, 3-1-1, Maidashi, Higashi-ku, Fukuoka City 812-8582, Japan; ${ }^{2}$ Department of Urology, Keio University School of Medicine, 35 Shinanomachi, Shinjuku-ku, Tokyo 160-8582, Japan; ${ }^{3}$ Medical Affairs KI Oncology, Bayer Yakuhin, Ltd., 1-6-5, Marunouchi, Chiyoda-ku, Tokyo 100-8265, Japan and ${ }^{4}$ Department of Strategic Investigational on Comprehensive Cancer Network, Interfaculty Institute in Information Studies/Science and Technology, The University of Tokyo, 7-3-1, Hongo, Bunkyo-ku, Tokyo 113-8654, Japan Correspondence: Katsunori Tatsugami (ktatsu@uro.med.kyushu-u.ac.jp)
} 
prospectively from more than 3200 patients and analysed retrospectively.

Study design

In this study, the background factors which affect the prognosis of patients with RCC were matched using propensity scores between $\geq 75$ and $<75$ years of age, and the patients' demographics, dose modification, AEs, tumour response, progression-free survival (PFS), and renal function (estimated glomerular filtration rate (eGFR)) were evaluated between these two groups.

Patients who had the following baseline data were selected for propensity score matching: Eastern Cooperative Oncology Group performance status (ECOG PS), tumour, node, metastasis (TNM) classification, prior surgery, prior systemic therapy, tumour histology, metastases (liver, brain, bone, and others (including lymph node)), C-reactive protein (CRP), and 1999 Memorial Sloan Kettering Cancer Center (MSKCC) risk. A total 1589 patients aged $\geq 75$ years and 397 patients aged $<75$ years were selected and were matched with each other, resulting in 397 matching pairs (794 patients). There were statistically significant differences in body weight and eGFR after matching because these two factors were excluded from matching due to possible physiological change by ageing.

The definition of observation period was the time from sorafenib treatment to the date of the final assessment of survival (if patient died, the date of death). The median observation periods (days (IQR)) before and after matching were 267 (286) and 266 (294), respectively.

\section{AEs}

AE grades were summarised based on the Medical Dictionary for Regulatory Activities (MedDRA), version 15.0, and classified as serious or non-serious. Serious AEs included (a) hospital admission or extended admission, (b) permanent significant dysfunction/ failure, (c) those that lead to congenital abnormalities, (d) other medically serious state, (e) life-threatening AEs, ( $f$ ) death, $(g)$ others that are medically regarded as important events or reactions.

Statistical analysis

Student's $t$-test or the Mann-Whitney $U$ test were used for continuous variables, and the $X^{2}$ test was used for categorical data. PFS was calculated using the Kaplan-Meier method. SAS version 9.1 or higher (SAS Institute Inc., Cary, NC, USA) was used for all statistical analysis.

\section{RESULTS}

Demographics in $<75$-year-old and $\geq 75$-year-old patients Before matching, each patient's demographics, excluding primary disease and metastatic site, differed between both groups. After matching, many of these differences between $<75$-year-old and $\geq 75$-year-old groups were removed, but not (mean \pm SD) age $(63.0 \pm 8.5$ years vs. $78.1 \pm 2.6$ years, $P<0.0001)$, body weight $(59.6 \pm 11.6 \mathrm{~kg}$ vs. $55.3 \pm 9.8 \mathrm{~kg}, P<0.0001)$, and eGFR $(53.7 \pm 19.5$ $\mathrm{mL} / \mathrm{min} / 1.73 \mathrm{~m}^{2}$ vs. $\left.47.5 \pm 15.5 \mathrm{~mL} / \mathrm{min} / 1.73 \mathrm{~m}^{2}, \quad P<0.0001\right)$, respectively (Table 1 ). The baseline co-morbidity of the patients was shown in appendix.

Treatment with sorafenib

Comparing the $<75$-year-old and $\geq 75$-year-old groups, there were significant differences in the median (IQR) starting dose (800 (0.0) $\mathrm{mg}$ vs. $800(400.0) \mathrm{mg}, P=0.2702)$ and median (IQR) daily dose (538.5 (400.0) mg vs. 422.3 (458.2) $\mathrm{mg}, P<0.0001)$, relative dose intensity (RDI) $(69.4 \%$ vs. $61.8 \%, P<0.001)$, and median (IQR) duration of treatment (7.6 (9.9) months vs. 5.6 (10.3) months) (Table 2). As for dose modification, the proportion of patients in whom the dose was reduced or interrupted was similar between the groups; however, the percentage of patients discontinuing treatment was significantly higher in the $\geq 75$-year group $(63.7 \%$ vs. $75.3 \%, P=0.0015)$. AEs accounted for more than half the patients discontinuing sorafenib treatment in both groups; this proportion was higher in the $\geq 75$-year group but this was not statistically significant (Table 2). In the $<75$-year group, the percentage of patients who discontinued due to insufficient efficacy was significantly higher than in the $\geq 75$-year group $(36.0 \%$ vs. $26.4 \%, P=0.0155$ ) (Table 2).

\section{Adverse events}

The most common among all AEs in the <75-year group compared with the $\geq 75$-year group were hypertension (33.3\% vs $37.3 \%$, respectively) and decreased appetite $(6.6 \%$ vs $12.9 \%$, respectively; $P=0.0027$ ). Alopecia ( $18.9 \%$ vs $11.8 \%$, respectively; $P$ $=0.0059)$, hepatic dysfunction (17.4\% vs $14.9 \%)$, and hypophosphataemia (9.6\% vs $5.3 \%$, respectively; $P=0.0214$ ) were more common in the <75-year compared to the $\geq 75$-year group, respectively (Table 3 ). As for serious $A E s$, there was no significant difference except for fever ( $0.8 \%$ vs $2.8 \%$, respectively; $P=0.0310)$ and renal failure/renal dysfunction ( $0.5 \%$ vs $2.3 \% ; P=0.0336)$.

\section{Tumour response}

Complete response (CR), partial response (PR), and stable disease (SD) rates in the $<75$-year and $\geq 75$-year groups were $1.9 \%$ vs. $3.6 \%, 24.2 \%$ vs. $26.7 \%$, and $60.2 \%$ vs. $56.4 \%$, respectively. Objective response rate $(C R+P R)$ and disease control rate $(C R+P R+S D)$ in the $<75$-year and $\geq 75$-year groups were $26.1 \%$ vs. $30.3 \%$ and $86.3 \%$ vs. $86.7 \%$, respectively. Overall, sorafenib treatment provided a similar tumour response regardless of age (Table 4). As also shown in Fig. 1, the median PFS in the $<75$-year and $\geq 75$ year groups was 217 days and 219 days, respectively, and the hazard ratio was 0.984 (95\% confidence interval $(\mathrm{Cl}): 0.817,1.184)$ (Fig. 1).

\section{Influence on renal function}

As the renal function of elderly patients may be significantly impaired before tyrosine kinase inhibitor (TKI) initiation and it has been reported that TKls might reduce renal function, we investigated whether sorafenib treatment impacted the renal function of these elderly patients, and monitored renal function by measuring eGFR during the observational period. The baseline eGFR of <75-year and $\geq 75$-year-old patients was 53.7 vs. $47.5 \mathrm{~mL} /$ $\mathrm{min} / 1.73 \mathrm{~m}^{2}$, respectively, and this did not decrease over a 12month period in either group (Fig. 2). When the eGFR of those who discontinued sorafenib treatment was analysed, it was not significantly changed from baseline (Fig. 2). This suggested that the maintained eGFR was not based on excluding low eGFR values of patients who dropped out of treatment.

\section{DISCUSSION}

A chronological age of 65 years or more is defined as 'elderly' or 'older people'. ${ }^{8}$ Recently, the definition of elderly people has been reconsidered due to the ageing population in Japan, and a proposal from the Japan Gerontological Society and the Japan Geriatrics Society is that the definition be changed as follows: 'preold age' 65 to 74 years, 'old age' 75 to 90 years, and 'super-old age' (or 'oldest-old age') more than 90 years. There have been a limited number of reports that showed the safety and efficacy of a TKI in RCC patients aged $\geq 75$ years. As for sorafenib, Procopio et al. performed comprehensive analysis of six clinical studies and two expanded access programs, and showed there was no difference in safety in patients aged between $\geq 75$ and $<75$ years. ${ }^{9}$ However, in this report, patients' demographic bias was not balanced by use of propensity score matching. Regarding another TKI, Miyake et al. reported the safety and efficacy of axitinib in $\geq 75$-year and $<75$ year-old RCC patients, ${ }^{10}$ but these data were from a single centre, and only 28 patients were aged $\geq 75$ years. Therefore, we 
Table 1. Patient characteristics

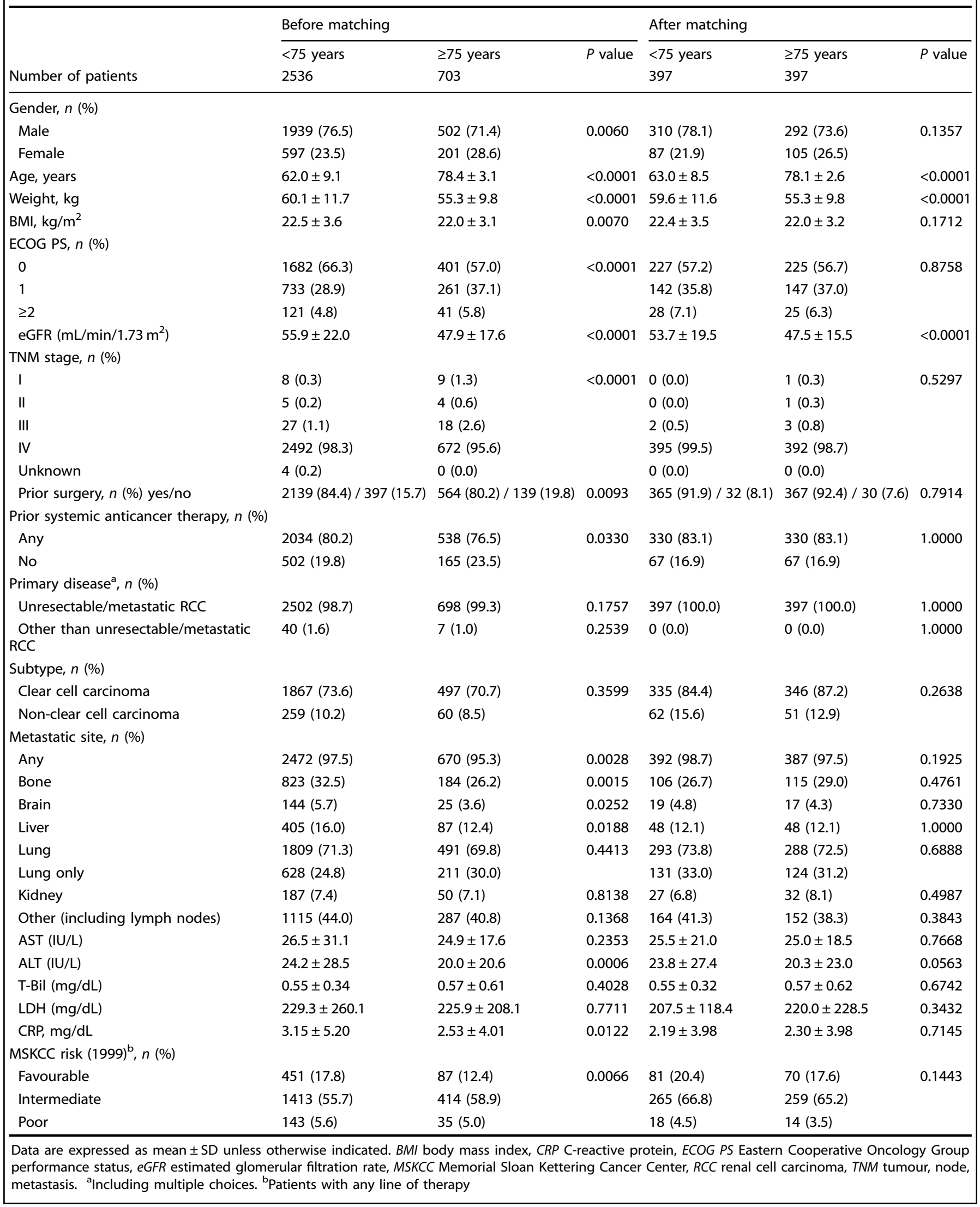


compared real-world data on the safety and efficacy of sorafenib in patients aged $<75$ and $\geq 75$ years using propensity scorematching analysis.

It is known that elderly patients with RCC often have comorbidities such as hypertension, cardiovascular disease and diabetes. ${ }^{11}$ Heng et al. reported that $35 \%$ of patients treated with molecular targeted agents in clinical practice did not meet the inclusion criteria of a general clinical study in terms of their comorbidities. ${ }^{12}$ Treatment efficacy such as tumour shrinkage, PFS, or overall survival in these patients was lower than that of elderly patients whose demographics were compatible with enrolment in

Table 2. Distribution of initial dose, median dose, dose modification, and reasons for treatment discontinuation

\begin{tabular}{|c|c|c|c|}
\hline & $\begin{array}{l}<75 \text { years }(N \\
=397)\end{array}$ & $\begin{array}{l}\geq 75 \text { years }(N \\
=397)\end{array}$ & $P$ value \\
\hline $\begin{array}{l}\text { Median starting dose, mg/day } \\
\text { (IQR) }\end{array}$ & $800(0.0)$ & $800(400.0)$ & 0.2702 \\
\hline $\begin{array}{l}\text { Median daily dose, mg/day } \\
\text { (IQR) }\end{array}$ & $538.5(400.0)$ & $422.3(458.2)$ & $<0.0001$ \\
\hline Relative dose intensity, $\%$ & $69.4 \pm 26.3$ & $61.8 \pm 28.0$ & $<0.0001$ \\
\hline $\begin{array}{l}\text { Median duration of treatment, } \\
\text { months (IQR) }\end{array}$ & $7.6(9.9)$ & $5.6(10.3)$ & 0.0123 \\
\hline \multicolumn{4}{|l|}{ Dose modification, $n$ (\%) } \\
\hline Reduction & $222(55.9)$ & $238(60.0)$ & 0.2501 \\
\hline Interruption & $164(41.3)$ & $186(46.9)$ & 0.1158 \\
\hline Discontinuation & $253(63.7)$ & $299(75.3)$ & 0.0004 \\
\hline \multicolumn{4}{|l|}{ Reason for discontinuation, $n(\%)$} \\
\hline AEs & $147(58.1)$ & $184(61.5)$ & 0.4117 \\
\hline Insufficient efficacy & $91(36.0)$ & $79(26.4)$ & 0.0155 \\
\hline Others & 29 (11.5) & 44 (14.7) & 0.2609 \\
\hline
\end{tabular}

a clinical study. ${ }^{12}$ For these reasons, the necessity for evaluation of the safety and the efficacy of molecular targeted agents in realworld clinical practice, with patients who might be excluded from clinical studies because of their comorbidities or complications becomes more important.

Although elderly patients are rarely excluded from the clinical studies of cancer because of their age, the numbers included may seem low because many were excluded due to comorbidities in their backgrounds. In the phase 3 TARGET study of sorafenib in patients with RCC, which had no age restrictions for enrolment, patients aged $\geq 65$ years accounted for only $27.4 \%$ of all patients, ${ }^{13}$ which is lower than the age distribution of RCC previously reported. ${ }^{14}$ Before matching in this study, patients aged $\geq 75$ and $\geq 65$ years accounted for $21.7 \%$ (703/3239) and 56.9\% (1842/3239), respectively (data not shown), which is higher than in the TARGET study, ${ }^{13}$ but lower than the age distribution of RCC ( $\geq 65$ and $\geq 75$ years: 69 and $40 \%$, respectively). ${ }^{14}$ The reason for the difference in age distribution in this study in comparison to other reports is that some physicians were less familiar with the use of sorafenib,

\begin{tabular}{|c|c|c|c|c|}
\hline & All & $\begin{array}{l}<75 \text { years } \\
(\mathrm{N}=397)\end{array}$ & $\begin{array}{l}\geq 75 \text { years } \\
(\mathrm{N}=397)\end{array}$ & $P$ value \\
\hline CR, n (\%) & $20(2.7)$ & $7(1.9)$ & $13(3.6)$ & 0.3883 \\
\hline PR, n (\%) & $186(25.4)$ & $90(24.2)$ & 96 (26.7) & \\
\hline SD, n (\%) & $427(58.3)$ & $224(60.2)$ & $203(56.4)$ & \\
\hline PD, n (\%) & 95 (13.0) & $50(13.4)$ & 45 (12.5) & \\
\hline$N E, n(\%)$ & $4(0.6)$ & $1(0.3)$ & $3(0.8)$ & \\
\hline ORR, \% & 28.1 & 26.1 & 30.3 & \\
\hline DCR, \% & 86.5 & 86.3 & 86.7 & \\
\hline
\end{tabular}

$C R$ complete response, $D C R$ disease control rate, $N E$ not evaluable, $O R R$ objective response rate, $P D$ progressive disease, $P R$ partial response, $S D$ stable disease

Table 3. Most common adverse reactions

\begin{tabular}{|c|c|c|c|c|c|c|c|c|}
\hline Adverse event & All & Serious & \multicolumn{2}{|c|}{$<75$ years $(N=397)$} & \multicolumn{2}{|c|}{$\geq 75$ years $(N=397)$} & $P$-values ${ }^{a}$ & $P$-values ${ }^{t}$ \\
\hline Hand and foot skin reaction, $n(\%)$ & $463(58.3)$ & $48(6.1)$ & $241(60.7)$ & $26(6.6)$ & $222(55.9)$ & $22(5.5)$ & & \\
\hline Hypertension, $n$ (\%) & $280(35.3)$ & $18(2.3)$ & $132(33.3)$ & $7(1.8)$ & $148(37.3)$ & $11(2.8)$ & & \\
\hline Rash, $n$ (\%) & $211(26.6)$ & $61(7.7)$ & $116(29.2)$ & $29(7.3)$ & $95(23.9)$ & $32(8.1)$ & & \\
\hline Diarrhoea, $n(\%)$ & $170(21.4)$ & $15(1.9)$ & $93(23.4)$ & $4(1.0)$ & $77(19.4)$ & $11(2.8)$ & & \\
\hline Alopecia, $n$ (\%) & $122(15.4)$ & $0(0.0)$ & $75(18.9)$ & $0(0.0)$ & $47(11.8)$ & $0(0.0)$ & 0.0059 & \\
\hline Hepatic dysfunction, $n(\%)$ & $128(16.1)$ & $44(5.5)$ & $69(17.4)$ & $24(6.1)$ & $59(14.9)$ & $20(5.0)$ & & \\
\hline Cytopenia, $n(\%)$ & $107(13.5)$ & $42(5.3)$ & $55(13.9)$ & $22(5.5)$ & $52(13.1)$ & $20(5.0)$ & & \\
\hline Bleeding, $n(\%)$ & $84(10.6)$ & $59(7.4)$ & $41(10.3)$ & $26(6.6)$ & $43(10.8)$ & $33(8.3)$ & & \\
\hline Decreased appetite, $n$ (\%) & $77(9.7)$ & $15(1.9)$ & $26(6.6)$ & $4(1.0)$ & $51(12.9)$ & $11(2.8)$ & 0.0027 & \\
\hline Dysphonia, $n$ (\%) & $52(6.6)$ & $0(0.0)$ & $20(5.0)$ & $0(0.0)$ & $32(8.1)$ & $0(0.0)$ & & \\
\hline Fever, $n(\%)$ & $45(5.7)$ & $14(1.8)$ & $17(4.3)$ & $3(0.8)$ & $28(7.1)$ & $11(2.8)$ & & 0.0310 \\
\hline Renal failure/renal dysfunction, $n(\%)$ & $23(2.9)$ & $11(1.4)$ & $6(1.5)$ & $2(0.5)$ & $17(4.3)$ & $9(2.3)$ & 0.0199 & 0.0336 \\
\hline
\end{tabular}




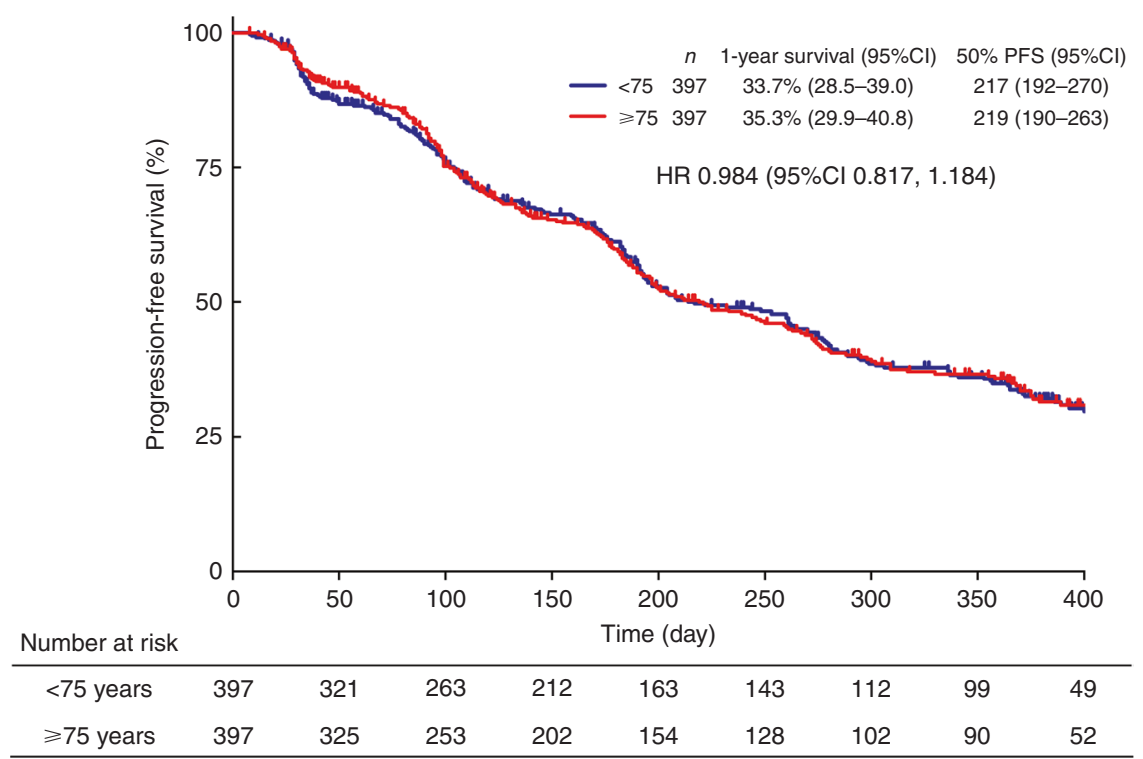

Fig. 1 Progression-free survival. PFS progression-free survival, $\mathrm{Cl}$ confidence interval, HR hazard ratio

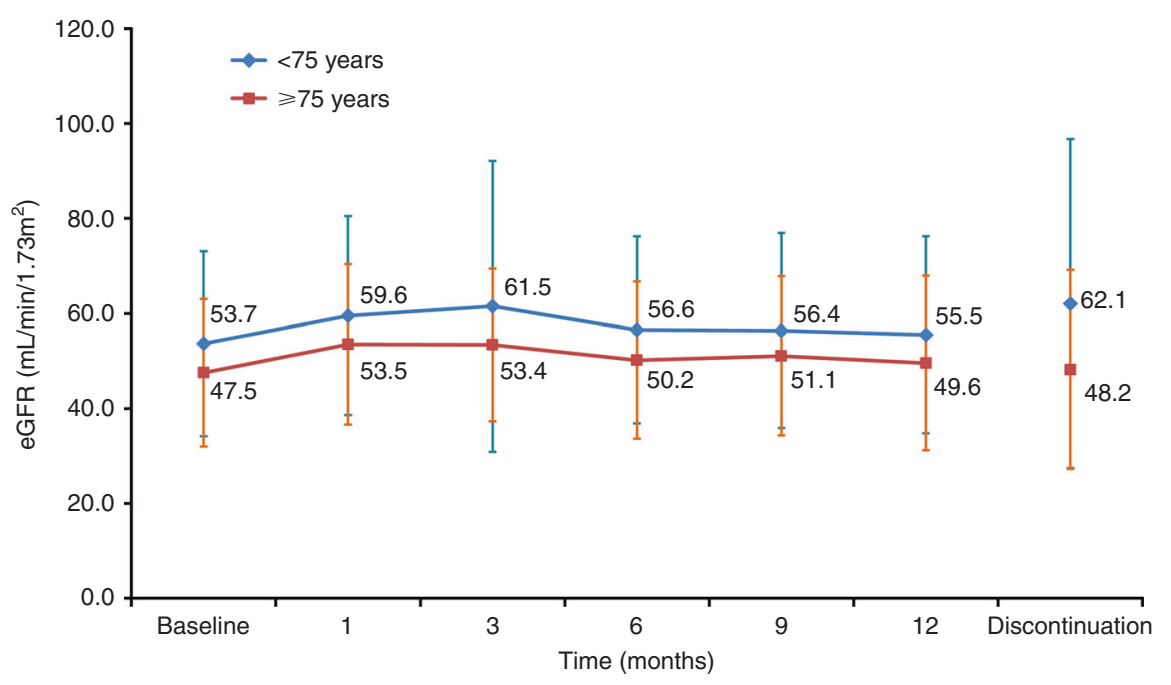

Fig. 2 Change in renal function of overall patients over time according to age. eGFR estimated glomerular filtration rate

because it had only recently been approved. Hence, there was some physician bias that impacted the number of elderly patients enroled.

In this study, there were significant differences in body weight and renal function between the $<75$-year and $\geq 75$-year groups before matching. To evaluate the impact of sorafenib on elderly patients with RCC, matching was conducted using the factors which were considered to affect the prognosis of these patients. Factors such as body weight and renal function which might change with age were excluded from matching because there would be a possibility to select specific population of elderly patients if these two factors were included in matching. Albiges et al. reported that the prognoses of metastatic RCC patients treated with targeted therapy were better in BMI $\geq 25$ group than those of $<25$ group. ${ }^{15}$ Although the frequency of those with $\mathrm{BMI} \geq 25$ was $17.1 \%$ (553/3239) in patients of this study, there was no significant difference in BMI after matching.

The lower starting dose for elderly patients might reflect the higher numbers of those with low body weight and reduced renal function. The number of patients who discontinued treatment was higher in the $\geq 75$-year group $(P=0.0004)$, but those who discontinued due to insufficient efficacy was lower in this group $(P=0.0155)$ (Table 2$)$. In clinical practice, even when patients had similar AEs, older patients may be more likely to discontinue treatment by the physician's decision or at their own request. Taking these situations into consideration, it might be difficult to continue the treatment of elderly patients while maintaining their quality of life and safety.

Generally, it is reported that there is a relationship between the anti-tumour effect of TKI and its $\mathrm{RDI}^{1{ }^{16-20}}$ however, in our study there was no significant difference in the anti-tumour effect in either group regardless of the lower RDI in the $\geq 75$-year group. Although the reason for this discrepancy is unclear, the optimal drug concentration might be changed due to decrease in renal or liver function in elderly patients; therefore, there is a possibility that a lower than usual dose might achieve a sufficient anti-tumour effect in this patient population. The fact that the frequency of hypertension, a predictive factor of TKI treatment, ${ }^{21-23}$ was higher in $\geq 75$-yearold patients reflected these physical status specific for elderly 
patients. As for the frequency of AEs during sorafenib treatment, hypertension and decrease in appetite were higher in the $\geq 75$ year group, but there was no significant difference for other AEs (Table 3). This indicated that sorafenib treatment could be effective in elderly patients with lower doses due to metabolism differences.

It is known that the pharmacodynamics of sorafenib differ among individuals, ${ }^{24}$ and the serum concentration of sorafenib might have been retained to similar level between the groups because of the difference of metabolism in liver, possibly accounting for the lack of difference in AEs rates. Although it is necessary to elucidate the plasma concentration of sorafenib, the data were not collected in this regard.

It is considered that TKls affect renal function because of their pharmacological mode of action. In the AXIS study comparing axitinib with sorafenib, an increase in serum creatinine of all grades was reported in 55 and $41 \%$ of patients, respectively. ${ }^{25}$ In the COMPARZ study comparing pazopanib with sunitinib, an increase in serum creatinine of all grades was reported in 32 and $46 \%$ patients, respectively. ${ }^{26}$ Since it is known that renal function may decrease in elderly patients, the impact of sorafenib on renal function was analysed. We found that the renal function remained stable in the $\geq 75$-year-old patients over the duration of sorafenib treatment; there was no significant decrease in eGFR at treatment discontinuation, which indicated that renal impairment was not a factor in treatment discontinuation. Sorafenib treatment for RCC in elderly patients appears safe with respect to renal function.

One limitation of this study was that it was retrospective without randomisation. Propensity score matching apparently shows similar outcomes as a randomised study, ${ }^{27}$ but it cannot be denied that there were some biases: those for whom the data of matching factors were missing at baseline were excluded from the analysis. In addition, prognostic factors were used as matching factors; however, other factors such as lower mean starting dose or higher drug discontinuation rate were not considered for propensity score matching. Also, as mentioned earlier, because these data were obtained just after the approval of sorafenib, a healthcare professional bias could exist, as physicians without wide experience of sorafenib were possibly included in this study. In addition, this study was based entirely on data derived from a Japanese population, and therefore the results are not necessarily applicable to non-Japanese patients.

We evaluated the safety and efficacy of sorafenib in elderly patients with RCC by matching patients' characteristics between two groups, aged $<75$ and $\geq 75$ years, using propensity score matching. Sorafenib was well tolerated in the $\geq 75$-year group, and efficacy, as measured by tumour response, was comparable to that in patients aged $<75$ years.

\section{ACKNOWLEDGEMENTS}

We thank the participating patients and staff of the study centres. Editorial assistance in the preparation of this manuscript was provided by ASCA Corporation, with financial support from Bayer Yakuhin, Ltd.; the authors retained editorial control over the content.

\section{AUTHOR CONTRIBUTIONS}

K.T. planned the data analysis, and M.O. and H.A. gave valuable suggestions and guidance to K.T. K.K. drafted the manuscript, which was further revised by K.T. All authors read and approved the final manuscript.

\section{ADDITIONAL INFORMATION}

Supplementary information is available for this paper at https://doi.org/10.1038/ s41416-018-0129-3.

Competing interests:: K.K. is an employee of Bayer Yakuhin, Ltd. The remaining authors declare that they have no conflict of interest.
Availability of data and material: : The data that support the findings of this study are available from the corresponding author upon reasonable request.

Ethics approval and consent to participate: On the basis of an instruction from the Pharmaceutical and Medical Devices Agency (PMDA) which is working together with Ministry of Health, Labour and Welfare in Japan, these data were collected and analysed. This study was performed in accordance with the Declaration of Helsinki.

Consent to participate: Written informed consents were obtained from the patients.

Consent for publication: There was no individual person's data in any form (including individual details, images or videos). All authors agree to its submission to the British Journal of Cancer and, if accepted, to its publication in this journal. We warrant that this article is original, does not infringe on any copyright or other proprietary right of any third party, is not under consideration by another journal and has not been previously published.

Funding: The financial support of this study and the preparation of the manuscript were provided by Bayer Yakuhin, Ltd.

\section{REFERENCES}

1. Cohen, H. T. \& McGovern, F. J. Renal-cell carcinoma. N. Engl. J. Med. 353, 2477-2490 (2005).

2. Ljungberg, B. et al. EAU guidelines on renal cell carcinoma: the 2010 update. Eur. Urol. 58, 398-406 (2010).

3. Altekruse, S. F. SEER cancer statistics review, 1975-2007. http://seer.cancer.gov/ csr/1975_2007/. (Accessed 20 November 2017).

4. Hutson, T. E. et al. Efficacy and safety of sunitinib in elderly patients with metastatic renal cell carcinoma. Br. J. Cancer 110, 1125-1132 (2014).

5. Bellmunt, J., Négrier, S., Escudier, B., Awada, A. \& Aapro, M. The medical treatment of metastatic renal cell cancer in the elderly: position paper of a SIOG Taskforce. Crit. Rev. Oncol. Hematol. 69, 64-72 (2009).

6. Akaza, $\mathrm{H}$. et al. A large-scale prospective registration study of the safety and efficacy of sorafenib tosylate in unresectable or metastatic renal cell carcinoma in Japan: results of over 3200 consecutive cases in post-marketing all-patient surveillance. Jpn. J. Clin. Oncol. 45, 953-962 (2015).

7. Oya, M. et al. Little impact on renal function in advanced renal cell carcinoma patients treated with sorafenib--analyses of postmarketing surveillance in japan in over 3,200 consecutive cases. Gan. To. Kagaku. Ryoho. 43, 559-569 (2016).

8. WHO. Proposed working definition of an older person in Africa for the MDS project. http://www.who.int/healthinfo/survey/ageingdefnolder/en/index.html (Accessed 20 November 2017).

9. Procopio, G. et al. Sorafenib tolerability in elderly patients with advanced renal cell carcinoma: results from a large pooled analysis. Br. J. Cancer 108, 311-318 (2013).

10. Miyake, H., Harada, K., Ozono, S. \& Fujisawa, M. Efficacy and safety of axitinib in elderly patients with metastatic renal cell carcinoma. Med. Oncol. 33, 95-101 (2016).

11. Coebergh, J. W., Janssen-Heijnen, M. L., Post, P. N. \& Razenberg, P. P. Serious comorbidity among unselected cancer patients newly diagnosed in the southeastern part of The Netherlands in 1993-1996. J. Clin. Epidemiol. 52, 1131-1136 (1999).

12. Heng, D. Y. et al. Outcomes of patients with metastatic renal cell carcinoma that do not meet eligibility criteria for clinical trials. Ann. Oncol. 25, 149-154 (2014).

13. Escudier, B. et al. Sorafenib in advanced clear-cell renal-cell carcinoma. N. Engl. J. Med. 356, 125-134 (2007).

14. Hori, M. et al. Cancer incidence and incidence rates in Japan in 2009: a study of 32 population-based cancer registries for the Monitoring of Cancer Incidence in Japan (MCIJ) project. Jpn. J. Clin. Oncol. 45, 884-891 (2015).

15. Albiges, L. et al. Body mass index and metastatic renal cell carcinoma: clinical and biological correlations. J. Clin. Oncol. 34, 3655-3663 (2016).

16. Kawashima, A. et al. One-month relative dose intensity of not less than $50 \%$ predicts favourable progression-free survival in sorafenib therapy for advanced renal cell carcinoma in Japanese patients. Eur. J. Cancer 47, 1521-1526 (2011).

17. Bellesoeur, A. et al. Critical role of sorafenib exposure over time for its antitumor activity in thyroid cancer. Invest. New Drugs 32, 569-572 (2014).

18. Boudou-Rouquette, P. et al. Variability of sorafenib toxicity and exposure over time: a pharmacokinetic/pharmacodynamic analysis. Oncologist 17, 1204-1212 (2012).

19. Rini, B. I. et al. Axitinib with or without dose titration for first-line metastatic renalcell carcinoma: a randomised double-blind phase 2 trial. Lancet Oncol. 14, 1233-1242 (2013). 
20. Sternberg, C. N. et al. Pazopanib exposure-response assessment as adjuvant therapy for patients with localized or locally advanced renal cell carcinoma (RCC) following nephrectomy. J. Clin. Oncol. 35, abstr. 4564 (2017).

21. Szmit, S. et al. Cardiovascular comorbidities for prediction of progression-free survival in patients with metastatic renal cell carcinoma treated with sorafenib. Kidney Blood Press. Res. 35, 468-476 (2012).

22. Rini, B. I. et al. Hypertension as a biomarker of efficacy in patients with metastatic renal cell carcinoma treated with sunitinib. J. Nat/ Cancer Inst. 103, 763-773 (2011)

23. Rini, B. I. et al. Diastolic blood pressure as a biomarker of axitinib efficacy in solid tumors. Clin. Cancer Res. 17, 3841-3849 (2011).

24. Strumberg, D. et al. Phase I clinical and pharmacokinetic study of the Novel Raf kinase and vascular endothelial growth factor receptor inhibitor BAY 43-9006 in patients with advanced refractory solid tumors. J. Clin. Oncol. 23, 965-972 (2005).

25. Rini, B. I. et al. Comparative effectiveness of axitinib versus sorafenib in advanced renal cell carcinoma (AXIS): a randomised phase 3 trial. Lancet 378, 1931-1939 (2011).

26. Motzer, R. J. et al. Pazopanib versus sunitinib in metastatic renal-cell carcinoma. N. Engl. J. Med. 369, 722-731 (2013).
27. Kuss, O., Blettner, M. \& Börgermann, J. Propensity score: an alternative method of analyzing treatment effects. Dtsch. Arztebl. Int. 113, 597-603 (2016).

(i) Open Access This article is licensed under a Creative Common Attribution 4.0 International License, which permits use, sharing, adaptation, distribution and reproduction in any medium or format, as long as you give appropriate credit to the original author(s) and the source, provide a link to the Creative Commons license, and indicate if changes were made. The images or other third party material in this article are included in the article's Creative Commons license, unless indicated otherwise in a credit line to the material. If material is not included in the article's Creative Commons license and your intended use is not permitted by statutory regulation or exceeds the permitted use, you will need to obtain permission directly from the copyright holder. To view a copy of this license, visit http://creativecommons. org/licenses/by/4.0/.

(c) The Author(s) 2018 